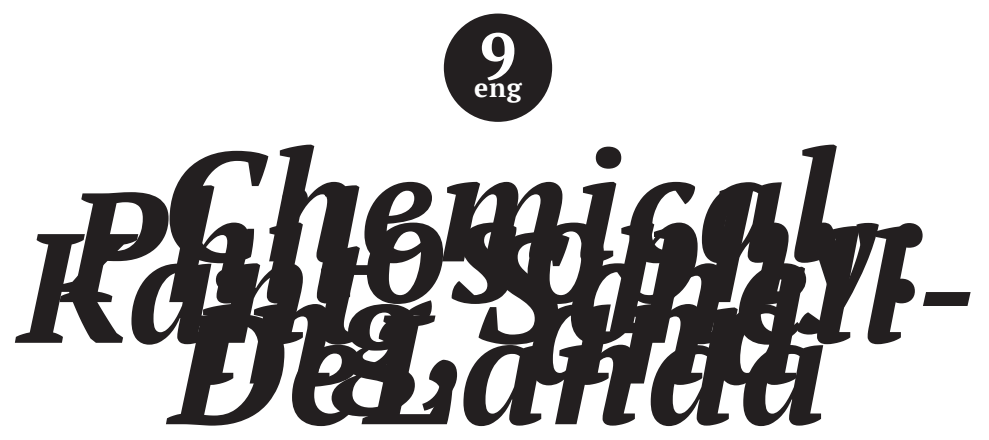

\author{
Ben Woodard \\ Researcher \\ IPK Leuphana University, \\ Universitätsallee 1, 21335 Lüneburg \\ E-mail:woodardbenjamin@gmail.com

\section{Chemical Philosophy: Kant, Schelling, and DeLanda}

\begin{abstract}
:
The following essay examines the role of chemistry as an arbiter between sense and cognition in the work of Immanuel Kant and F. W. J. von Schelling. Kant's well-known and decidedly lukewarm treatment of chemistry not only affects the relation between philosophy and science more broadly, but has important

consequences for how to think of the relationship between the formal structures we can derive from sense as articulated

by philosophy and how these conceptual forms give sense (scientifically coded as observation) a regulative function to discriminate particular scientific domains and/or fields from one another.
\end{abstract}

Keywords:

Chemistry, Kant, Schelling, DeLanda, philosophy of science 
The following essay examines the role of chemistry as an arbiter between sense and cognition in the work of Immanuel Kant and F. W. J. von Schelling. Kant's well-known and decidedly lukewarm treatment of chemistry not only affects the relation between philosophy and science more broadly, but has important consequences for how we want to think of the relationship between the formal structures we can derive from sense as articulated by philosophy and how these conceptual forms give sense (scientifically coded as observation) a regulative function to discriminate particular scientific domains and/or fields from one another.

This entails an attempt to see, or at least demonstrate, the conceptual force of chemistry through its history and thereby treat concepts as having causal force. One should provide a theory of chemistry in terms of how it changes the central access point that allows it to take place, which, arguably, is that of our empirical senses. Thus the history of chemistry I give here hopes to show how chemistry is a complexification of how we sense sensation's structure and how we think cognition as the experimental results of our changing capacities to sense anything. The practical result of this is a refusal of the separation between the philosophy of science and history of science other than as modes of the same mental-chemical process.

In terms of the history of chemistry, the relative shift from a quantitative to a dynamic conception of chemistry in the eighteenth century also maps onto a shift from a staunch division of normative and natural domains of investigation to a monist spectrum enabling forces and materials that constitute the possibility of all cognition (normative and otherwise). This shift of the limits of the sensible and the consciousness of the sensible can be tracked through a comparison of Kant and Schelling's attitudes toward chemistry.

Finally, by examining Manuel DeLanda's recent text Philosophical Chemistry (2015), one can see how a contemporary attempt at thinking chemistry outside of the context of Kant and post-Kantian thought fares in terms of the limits of sense. My aim in the following is to argue that chemistry forces a conceptual change within philosophy concerning the role of sensation as part of the genesis of ideas as much as scientific practices. This is most apparent in Schelling's work due to the destabilization of substance, as such, by way of the chemical experimenter.

One can begin, then, by examining the history of chemistry as simultaneously a history of a field of science as well as a history of the domain of the chemical as a bridge between sensation and thought beyond a standard empiricist or rationalist formulation. 


\section{From Alchemy to Kant}

Prior to the emergence of chemistry proper, alchemy functioned as a kind of pre-chemical practice that was mostly concerned with the transmutation of the elements, most notably of non-precious into precious metals (famously of lead into gold). Philosophically, alchemy and chemistry can be traced back at least as far back to the Ionian Natural Sciences (which some have argued still function as a direct influence on Schelling) where thinking alchemically about nature meant focusing on the combinatorial possibilities of fundamental substances (different amounts of air, water, fire, earth - or aperion, in the case of Anaximander).

Over time alchemy became more and more concerned with medicinal practices as well as more finely grained (not strictly elemental) accounts of substantive transformations (what would later be called chemical reactions). While the standard history of alchemical practices emphasizes that the transformative capacities of one element to another was driven by economic and psychological curiosity, the medical applications of alchemy index its bonds to the limits of sensation. Paracelsus's medical project centered on humors (fluid and mineral balances in the body) and use of mercury, sulfur, and salt introduced more of a non-western influence into the practice of alchemy (Cobb and Goldwhite 2002: 97, 132). Humors functioned as complex conceptual-experimental gateways between the chemical, physiological, and mental domains. For our purposes, Paracelsus marks an important step in what were considered substances outside the body becoming internalized, thereby setting up alterable relations between one's capacities and perceptions and the chemical constitution of one's own body.

The rise of scholastic and rationalist approaches in natural philosophy that followed then carved up the alchemical field into multiple more manageable practices. It was not only a theological and rational separation of rational soul and matter that engendered such shifts, but the concomitant formalization of laboratory practices and rigorous measurement schema (with Ramon Lull and Francis Bacon being pseudo-precursors). This rise of the efficacy of experimental reason can be found in the examples of Bernoulli's vat, Otto von Guericke's air pump (to be later made famous by Robert Boyle), and Dom Perignon's cork (Cobb and Goldwhite 2001: 114). Furthermore, Boyle played a large role in the Royal Society formed in 1665 that drastically helped to institutionalize chemistry and the physical sciences in general (Ibid: 120).

While this institutionalization is easily considered as only part of the monetization and capitalization of chemistry, for our purposes 
here it is important to keep in the mind the correlated complexification of the sensorial. Perignon's cork is a manufacturing process as much as it is the loosening of the social and a pleasant derangement of the senses. One would be equally hard pressed to deny the experiential change made possible by the chemical capacities of a master perfumer. The persistent question of chemistry is not only how it developed as a field of knowledge but how its practices developed our understanding of the chemical as part of our sensory capacities. In other words, chemistry teaches us how to sense.

But, of course, methods, instruments, and institutions did not fully decide the direction of investigation into the chemical domain. Questions of the general nature of chemical concepts remained philosophically or intellectually determined due to the complexity of the known unknowns compounded by the unknown unknowns. Hence why serious attempts at a systemization of the chemical process began with the advent of phlogiston (Cobb and Goldwhite 2001: 123), proposed by Johan Becher in 1667 as an element contained within combustible bodies to explain their flammable nature. This was supported by some chemists who made important developments in spite of it, such as Joseph Black who argued against thinking of the chemical in terms of the elements but instead as classes (Ibid: 137). The Russian chemist Mikhail Lomonosov's challenges to phlogiston would later be confirmed by Antoine Lavoisier through the computational tools of atomistic chemistry. It is important to point out how phlogiston can be considered a placeholder concept, one that united various problems and procedures. To dismiss it as wrong engages in Whiggish history and in turn suggests that our epistemological position is complete or almost complete.

More experiments in pneumatic chemistry meant a shifting experimental focus from fire to air (Ibid: 134), following from earlier theories of Johannes van Helmont and others, such as the aforementioned Black, as well as Daniel Rutherford who attempted to parse out good air (or common air) from bad air or gases such as nitrogen with similar experiments done by Henry Cavendish with hydrogen in the late 1700s (Ibid: 143).

Around the same time French revolutionary chemistry quickly made substantial discoveries, many by Lavoisier, the so-called father of modern chemistry. Lavoisier's water transmutation experiment resulted in the concept of the conservation of mass (Ibid: 154), which he measured with the help of the young astronomer and mathematician Pierre Laplace (Ibid: 160). Transmutation suddenly suggested a radical sameness over a radical difference, a unity suggested in phlogiston theory but too hastily constructed, since 
processes (such as heating) could produce different elements with no measurable loss of mass. Lavoisier's work was further developed by Joseph Proust's experiments on definite proportions (Ibid: 176), as well as John Dalton's reintroduction of the concept of the atom as steps toward quantification (Ibid: 177).

Yet, as we shall see below, the exploration of chemistry was not only guided by a nascent atomism but also by approaches emphasizing forces and fields. This parallelly divided paths in the development in physics and with it highlights whether chemistry was and should be thought of as a subsidiary science to physics.

In terms of the domain of the sensible, it became a question not only of method but of how much explanatory weight one put on the discontinuous plurality of substances and qualities as well the work of the investigator's mind. In general the atomistic approach assumed a fundamental difference between observation and observer while an emphasis on forces or fields required more oblique practices such as Benjamin Franklin's famous kite flying and Leiden jar experiment, which prefigured the study of electrical phenomenon by Volta and Galvani (Ibid: 179-80). In essence, both approaches took on the problem of whether discontinuity or continuity existed at the level of the physical and whether this changed at different domains. Or, in other words, did the plurality of chemical substances exist merely as expressions of physical laws, or did their relation point to a chemical affinity that in turn was related to an organic continuity?

The development of electrochemistry coincided with the rise of professional or industrial chemistry (Ibid: 185), which, in the period just prior to and during Schelling's primary writings on chemistry, was going through a phase in which industrial chemistry was being combined with Romantic modes of thinking (Ibid: 186). The oblique approach of Romantic science stresses how an emphasis on the observer was not a rational space of measurement, but a search for the grounds of subjectivity outside its usual sources. Such Romantic figures included Humphrey Davy (Ibid: 189-90), who saw light as substance and electricity as passing through electrical fluid (though correctly surmising that heat was motion and not substantive), and Michael Faraday (who worked on the border between physics and chemistry), who conducted experiments on the decomposition of materials by electricity (electrolysis) and was inspired by Hans Christian Oersted's demonstrations of electromagnetism (Ibid: 198-99).

But what is the importance of Kant's and certain post-Kantian views of chemistry other than as a historical exercise? Along with many contemporary philosophers both analytic and continental, there is some value in undertaking a philosophy of science that fol- 
lows a naturalized version of Kant's transcendental schemata. At the same time, the fact that Kant is still a man of his time and, as a result, he may not have viewed chemistry as a proper science, raises questions about how context inexpedient the constructive aspects of his transcendental accounts are, how resistant they could or should be, to scientific advancements? The complication, as has already been suggested, is what happens when the construction of a transcendental apparatus, which depends upon a scientific understanding of sense, instigates a change in that understanding? But while a philosophical or conceptual apparatus should survive and even engender new discoveries, what does it mean if a conceptual schema does not include an entire field of inquiry such as chemistry?

Whether Kant considered chemistry a proper science remains an open debate. In terms of the letter of Kant's work, we can say that chemistry never achieves the status of a proper science. However, as it has been argued, he was clearly interested in the developments of chemistry and, in his last work written before his death it is suggested that Kant may have, in the end, considered chemistry a science in the proper sense (or at least that it could become a rational science). So, while Kant in 1786 in the Metaphysical Foundations of Natural Science does not see chemistry as a science, one could argue that the Kant of the 1803 Opus Postumum did.

It has been well documented by Michael Friedman that Kant kept up with developments in chemistry in both Germany and France. He was familiar with Ernst Stahl's theories and, during his critical period, shifted from Stahl's work, which emphasized types of elements, to Lavoisier's atomistic account, as well as the latter's discussions of caloric theories of matter (which, arguably, was a critique, and transformation of, phlogistic accounts of the elements). So, while Kant clearly saw that chemistry had an internal structure of communal and rational practice developing historically, he states in the preface of the Metaphysical Foundations:

What can be called proper science is only that whose certainty is apodictic; cognition that can contain mere empirical certainty is only knowledge improperly so-called. Any whole of cognition that is systematic can, for this reason, already be called science, and, if the connection of cognition in this system is an interconnection of grounds and consequences, even rational science. If, however, the grounds or principles themselves are still in the end merely empirical, as in chemistry, for example, and the laws from which the given facts are explained through reason are mere laws of experience, then they carry with them no consciousness of their necessity (they are not 
apodictally certain), and thus the whole of cognition does not deserve the name of a science in the strict sense; chemistry should therefore be called a systematic art rather than a science. (Kant 2004: 4)

The tempting word to assert here is "yet." Nothing Kant says would seem to preclude chemistry from becoming a proper science on Kant's own terms. While he acknowledges that chemistry has principles, that it can more or less predict how substances will react, and classify chemicals and solutions accordingly, he does not think chemistry can sufficiently say why this occurs (hence his brandishing of apodictic and, later on, a priori).

In some sense, it is not difficult to sympathize, at least partially, with Kant's skepticism. In Kant's lifetime, while the developments between Boyle's The Sceptical Chymist (2013) and Lavoisier's experiments in combustion, the nature of chemistry as both a field (as a set of agreed upon practices and pursuits) and a domain (its place in nature, its laws, etc.) remained uncertain. What is odd is that only a few pages later, Kant takes a harder stance regarding the possibility of chemistry becoming a science. The fundamental issue for properly linking the practice or field of chemistry to its scientific status was the lack of appropriate mathematical measurements. While Kant of course did not doubt the empirical accounts of chemical affinity and of the penetrability of one substance into another, or the decomposition of one chemical by another, he lamented the incomplete attempts at quantifying these relations and processes: chemistry for Kant can be nothing more than a systematic art

[...] or experimental doctrine, but never a proper science, because its principles are merely empirical, and allow of no a priori presentation in intuition. Consequently, they do not in the least make the principles of chemical appearances conceivable with respect to their possibility, for they are not receptive to the application of mathematics. (Kant 2004: 7)

As Kant explains, a rational or proper science requires equal grounding in empirical material and a priori intuitions, intuitions that determine the very possibility of a field's concepts proper to its domain. But, if mathematical imprecision was the sole gap between chemistry-as-art, and chemistry-as-science, why would Kant claim, seemingly by fiat, that chemistry could never be a science?

In the Opus Postumum (1993), Kant discusses chemistry in relation to physics and, in particular, in relation to the dissolution of bodies and the notion of caloric matter. In a brief discussion 
of dissolution early in the Opus, Kant defines chemistry as merely "the science of the inner forces of matter" and discusses it primarily in terms of the dissolution of matter either in quantitative or qualitative terms (1993: 5). Kant outlines chemistry as treating dissolution as the separation of types of matter where a quantitative dissolution is tied to a phase change, and a qualitative change would be a change in the type of matter (Ibid). The fact that Kant relies on language of forces, repulsion, and attraction, foregrounds his later discussion of chemistry as a type of physics in which chemistry is physics in its merely empirical sense (Ibid: 50). While Kant would seem to be repeating his earlier attitudes toward chemistry, some important changes emerge. The mentions of the quantitative likely speak to Kant's recently gained familiarity with Lavoisier's atomistic chemistry. But the discussion of changes in the type of matter seem to complicate his relegation of chemistry to empirical physics.

This is further confirmed in Kant's more extensive discussion of chemistry in the Opus in regard to caloric matter (Ibid: 47-48). The caloric theory of heat is generally treated as an outgrowth of the above-mentioned theories of phlogiston, and as a kind of transitory theory in the history of thermodynamics (between phlogiston and the mechanical theory of heat). Thus, we are put in a tricky historical position of knowing that it is perfectly reasonable for Kant to treat chemistry in at least some senses as being reducible to physics, at least when it comes to thermodynamics. But, given that thermodynamics proper did not exist, can we take Kant's assertion about the impossibility of chemistry to become a science as retroactively justified by the later emergence of thermodynamics?

There is also a larger issue that can be seen as superimposing the debate about the status of chemistry, which is exactly how Kant wishes to connect the Metaphysical Foundations (2004) with the Opus, or how he wishes to connect the critical project back to the physical sciences without falling back into a precritical rationalist position. ${ }^{1}$ This bridging, or potential extension of the critical project is problematically (at least from our present point of view) built upon a systematized collection of empirical facts (Ibid: 13), that itself relies upon a theory of caloric matter that Kant argues penetrates all of space, and is the basis for the very possibility of representation (Ibid: xl). While Kant entertains a similar line of argumentation in the opening pages of The Critique of Judgment (2002), there he focuses on reflection and the unity of experience for the subject.

\footnotetext{
${ }^{1}$ I discuss this at length in Chapter 2 of my Schelling's Naturalism (2019).
} 
The physical status of this caloric matter is questionable as it is not only material and all-penetrative but is also described, in more idealistic terms, as a hypostatization of space itself (Kant 1993: 71). Thus, in the Opus, it is hard to distinguish the critical, that is, representational need for the ether from its physical necessity. While Schelling, as we will see below, weighs heavily on the side of physical necessity, he is able to do this by leaning on a dynamical physicality over, and against, Kant's reliance on mechanics and kinematics, thereby keeping the dynamic philosophy separate from physics (such as under the name of phoronomy, or the a priori study of movement). ${ }^{2}$

This brings us to the problem with which we began and leads into the discussion of Schelling's views of chemistry. The caloric theory of matter could be read as potentially reducing chemistry to physics (and hence would make chemistry a proper science only to the extent that it would be an applied form of physics) or, read against the grain of the critical project, it could also be used to make chemistry a proper science that makes sensibility as such measurable through the further developments of chemistry with but beyond mechanics.

Michel Bennett McNulty (2016) argues that chemistry still fails to be a proper science for even the Kant of the Opus because it still lacks a priori laws and may still fall short of the mathematization condition (that is, it cannot be straightforwardly mathematized like Newtonian physics). But we can still wonder how much of this is about Kant's standard for chemistry or about his knowledge of chemistry relative to that standard? McNulty argues that Kant was familiar with the statistical chemistry that preceded Lavoisier's work, such as in Boyle and Hales (McNulty 2016: 70). According to McNulty, the problem is not that chemistry is insufficiently mathematical but that its mathematics of quantity (and of Lavoisier's scale, of the proportions of mixtures) does not issue an accompanying a priori law that can illuminate the internal dynamics of matter expressed by the caloric.

Here is where Kant can be seen as simultaneously moving toward the naturephilosophical project, but perhaps also sticking to his qualifications for science. While Kant is willing to admit that matter is ultimately a question of forces, he is not willing to say those forces are constitutive of matter, or that we can think about forces outside of a context of substantial stuff. Part of the question then

${ }^{2}$ In this sense, the sublime, as a kind of formless object (operating in the matterexperience role of the Opus), shifts between the mathematical and the dynamic, whereas these domains are brought arguably closer together in the Opus. See Kant (1993: 128-34 [5:244-2:251]). 
becomes whether Schelling simply violates the Kantian strictures or whether he responds to the post-Kant developments in chemistry in the spirit of Kant. Both Frederick Beiser (1993) and Michael Friedman (2007) for instance argue that Schelling merely expands upon the dynamic theory of matter. ${ }^{3}$

\section{Schelling on Chemistry}

By building on Kant's interest in dynamics, Schelling pushes the transcendental into naturalist territory by way of chemistry, for instance when he summarizes his views in claiming that chemistry is sensory dynamics made intuitable (1988: 257). In this regard, Schelling is unwilling to separate chemistry from not only qualitative shifts in perception but also claims that the domain of the chemical partially grounds perception and subsequently all organic consciousness. For Schelling, then, any epistemological discovery is accompanied by an update in how nature deeply affects our capacity for thought.

Schelling's interest in the chemical cannot only be relegated to his early work and the notion of naturalizing sense and consciousness is not a reductive move, but demonstrates how the access to sense often requires oblique approaches. A shallow survey of the effects of psychedelics or even less spectacular pharmaceuticals demonstrates how chemistry can not only tell us something about how sense functions chemically but also gives us different notions of sense. As Michael Friedman puts it:

Schelling's particular intervention therefore consists in the way in which he responded to the deep philosophical problems created by Kant's sharp distinction between constitutive principles and regulative principles, on the one hand, while simultaneously engaging with the newest developments at the forefront of electrochemistry, on the other. Kant's own attempts further to develop his system so as to resolve both the philosophical problems in question and to accommodate recent scientific results had led him, as we have seen, right up to the verge of the radically new conceptual situation faced by Schelling, Ritter, and Oersted. Nevertheless, the decisive step of conceiving magnetic, electrical, and chemical or galvanic effects in terms of a triadic continuation of a dialectical process beginning with the fundamental forces of attraction and repulsion in general

${ }^{3}$ Michael Massimi sees traces of such a theory in Kant's precritical works as well. See Kant's dynamical theory of matter in 1755 , and its debt to speculative Newtonian experimentalism. 
is one that Kant did not and could not take - and it is was just this crucial step that was then left to Schelling alone. (Friedman 2007: 67)

This Romantic state of chemistry is what Schelling engages with in the Ideas for a Philosophy of Nature written in 1797 (with additions in 1803 [1988]) and First Outline of a System of the Philosophy of Nature in 1799 (with the introduction written later that same year [2004]), an attempt at combining industrial productivity with Romantic or ideal systemization. Extensive and organized experimentation in the physical sciences with a not-yet-completely solidified or incontestable set of laws (but only competing approaches) allowed Schelling to discuss life and organicism beyond both vitalism and mechanism. This allowed him to posit a fundamentally dynamic nature that produces things or figments of reality (Scheinprodukt), which are themselves only a shadow of nature's total power, as they are not in themselves scientifically or substantively substantial, but a kind of indicator of the possible paths of nature. Two quotes from the Ideas for a Philosophy of Nature illustrate this purportedly grand imperative: "The whole material Universe branches out from the highest unities into particular universes, because every possible unity breaks up into other unities, of which each can appear as the particular one only through continued differentiation" (Schelling 1988: 151), and later on: "The root and essence of Nature is that which combines the infinite possibility of all things with the reality of the particular, and hence is the eternal urge and primal ground of all creation" (Ibid: 272-73).

But before charting the more detailed conceptual stakes of Schelling's dynamism and how it relates to chemistry and the chemical process, it is prudent to examine exactly what Schelling takes from which scientists in Naturphilosophie. That is, to diagnosis the philosophical state of chemistry according to Schelling.

The emphasis on the issue of sense and the physiological is evident from the scientists that populate the appendix of the First Outline as they are largely physicians. John Brown (the proponent of organic excitability) is the most discussed of the lot in the First Outline and is usually praised for discovering, or at least pointing to, excitability but critiqued from not adequately mining its philosophical ground (Schelling 2004: 66). Furthermore, Brown's principles are praised but Schelling laments the fact that he does not construct a system of excitability that, according to Schelling, should not be restricted to physiology (Schelling 2004: 111). Likewise, Johann Christian Reil is critiqued for over selling the ubiquity of the chemical process, or at least of chemistry proper (Ibid: 57). 
Schelling's whole analysis of chemistry and of the natural sciences in general is focused primarily on the conceptual limitations of the various theories used by physical scientists. While philosophers cannot and should not tell scientists or Naturphilosophen how to do their work, it is their job, according to Schelling (2004: 199), to point out how much can be drawn from conceptual resources alone. One complex version of this is that Schelling thinks that natural scientists should not rely upon substances as fundamental or as explaining processes merely by grounding them. For Schelling, fundamental substances or objects would seem to disrupt the plural and constant dynamic creation that lies at the heart of nature. If a substance was fundamental then it would have no proper genesis, it would essentially be the ground of itself. These substances would then have to have constructive and synthetic powers over each other and generate other substances without being subjected themselves to such changes. This for Schelling is a denial of the radical character of nature itself.

The radical nature of chemistry, while addressed obliquely in the First Outline via physiology, truly emerges in the Ideas as it is far more concerned with chemistry proper. Schelling celebrates Lavoisier (as well as Wilhelm von Humboldt) for suggesting the reactive (in their case carbon) composition of living things, which in turn means that chemistry can lead to an entirely new system of nature (Schelling 1988: 62). Here Schelling is more critical of the aforementioned theories of phlogiston while appreciating them as a connective idea (or model), he is clear that new developments in chemistry rightly challenge its apparently imaginary status. Lavoisier's chemistry represents a new form of ideal connectivity between the chemical elements and the other sciences while also letting the explanatory ground of chemistry open to other sciences (especially physics). As Schelling writes regarding the application of the philosophy of chemistry in the Ideas after criticizing mechanical chemistry:

The dynamical chemistry, on the other hand, admits no original matter whatever - no matter, that is, from which every else would have arisen by composition. On the contrary, since it considers all matter originally as a product of opposing forces, the greatest possible diversity of matter is still nothing else but the diversity in the relationship of these forces. (Schelling 1988: 221)

Lavoisier represents many of the chemical and physiological facts presented in the First Outline, such as the electro-chemical relation 
of two near bodies and the effect light and electricity has on vital air (Ibid: 247-48), the phosphoric disintegration also related to the work of Agrand (Ibid: 71) or the decomposition of water by Cavendish (Ibid: 108). Schelling (Ibid: 226) utilizes the work of Joseph Black to explain fire as movement, thereby indexing Faraday's aforementioned musings on heat-as-movement or following Georges-Louis Leclerc, Comte deBuffon's suggestions of all matter collapsing into light (perhaps foreshadowing Proton decay and the end of chemistry as such) (Ibid: 77, 224), but Schelling leaves Buffon behind when he tries to assert the attractive force over the repulsive (a non-generative duality that Schelling cannot abide) (Ibid: 186). Schelling utilizes Adair Crawford's experiments on heat-as-quality to describe the oddly qualitative nature of heat itself (Ibid: 227-31), and also discusses Joseph Priestly's work on the nature of electricity and its relation to heat and light (Ibid: 110-11).

Here it will serve to oscillate back to the broader metaphysical scheme of Schelling's Naturphilosophie in order to bind these instances of chemistry in terms of a broader dynamics. That the chemical, the electrical, and the magnetic (or we might say how chemistry, biology, and physics interrelate) all informed and crossed into one another yet remained distinct provided apt ground for Schelling's dynamic yet graduated view of nature, an original unity (united in its objective being but always divided or potentiated in its active or subjective state) that is productivity.

In the First Outline, Schelling writes: "there must be one force that reigns throughout the whole of nature and by which Nature is preserved in its identity; a force that we have not yet deduced, but to which we find ourselves driven for the first time. However, this force may be capable of an infinite amount of modifications and may be as various as the conditions under which it operates" (Schelling 2004: 79). Immediately the issue for Schelling is the unavoidable task of Naturphilosophie as construction. While nature exists first in some kind of tension and decomposes into forces, these forces (of which we are not sure how many there are) always remain (at bottom in their nature) ultimately ungrounded. The determination of their conditions remains always a retroactive construction given the form of their construction as observed through effects (i. e., in the empiricism of the experiment and the realm of ideality).

So when Schelling discusses different sciences, sciences as working within various domains of forces, it is always toward an integration (he writes: " $t]$ here has long been a theory that the magnetic, electrical, chemical and, finally, even the organic phenomenon are interwoven into one great interdependent whole. This must be es- 
tablished." [Ibid: 242]). Schelling then relates this to substantiality, actuality, or matter (in the not-strictly-dynamic sense) when he writes: "Inorganic nature brings forth the whole wealth of its products only by changing the relation of those three functions of matter to infinity; for magnetism, electricity, and chemical process are the functions of matter generally, and on that ground alone are they the categories for the construction of all matter" (Ibid: 244, n53). This impulse is similar to a passage in the Ideas where quantitative motion is explained by gravity, qualitative motion by chemical process, and relative motion by mechanics (Schelling 1988: 22).

Chemistry then represents the dynamics of experience (or sensory dynamics), which I will address below, meaning that on the one hand chemistry is only one possibility, one series opened as a result of more base natural tendencies (magnetism, gravity) but, because of its nature as leading to the experiential operation of the organic (and arguably perhaps the inorganic as well, in terms of chemical processes relating to heat and light), it is that regime of Naturphilosophie which is the most demonstrative, it is a dynamic that paints the very structure of perceptual dynamics in chemical reactions.

But then how does the formal (whether thought broadly in terms of epistemology or more specifically in Kant's transcendental formulae) get a grip on the ever-shifting dynamics of the chemical world and the evidence of sense, once we have learned it is at the whim of chemical dynamics. While transcendental philosophy and a philosophy of nature are formally separate, or we might say operationally separate (Grant 2006: 174), they do not speak to two different worlds but only to two different functional regimes; transcendental philosophy is the dynamics (and history) of the mind. In his excellent Philosophies of Nature after Schelling (2006), Iain Hamilton Grant writes: "the final phenomenal link between the act of thinking and the experience of the content of thought has been broken; to reinstate it is thereafter the function of transcendental philosophy, the only science with such a 'double series.'” (2006: 54). That exists unity is a fact of the absolute, but to limit unity to a particular regime, to submit a set of activities to a definite ground, is an act of transcendental philosophy, whereas Naturphilosophie feverishly digs beneath itself in a frenzy of ungrounding and vivisects all instances of apparent permanence (such as substance or element), all products, as merely indicators of something deeper.

Relating this unity to organicity, Schelling writes in the Ideas: "form and matter are inseparable [...] every organization is a whole; its unity lies in itself, it does not depend on our choice" (Schelling 1988: 31), but at the same time unity is a concept, and something 
constructed by us through reflection (Ibid: 31-32). This relation of the absolute ideal and the absolute real is a linchpin to philosophy itself and to philosophy as a science (Ibid: 44). Or, as Schelling puts it earlier in Ideas: "we require to know, not how such a Nature arose outside us, but how even the very idea of such a Nature has got into us; not merely how we have, say, arbitrarily generated it, but how and why it originally and necessarily underlies everything that our race has ever thought about Nature" (Ibid: 41). This productive unity is also how Schelling opens the chapter on Natural Science in On University Studies (1965). Here we see the validity of Grant's simple statement "nature thinks," or, more disruptively, we do not think, nature produces the process of thought through us, a process that makes an object of itself in idealism. This has strange consequences of any atomistic or quantitative theory of the chemical. Schelling writes: "The individuality of the original actants however, strives against this universalization. The individuality of all actants ought to be maintained in the absolute product together with the most complete combination" (Schelling 2004: 28). So, in one, very physical or metaphysical, sense, it would appear that we have some granules in the flow of becoming, yet this cannot be taken to be ontological in the same sense that nature as massive Proteus is (Ibid). Toward the end of the First Outline, Schelling writes: "This idea of pure intensity is expressed by the idea of the actant. It is not the product of this action that is simple, but the actant itself abstracted from the product, and it must be simple in order that the product may be infinitely divisible" (Ibid: 208). Grant takes issue with the articulation of actants as natural monads in his Philosophies of Nature after Schelling: "The units of activity' or natural monads effectively recover the Kantian project in the Physical Monadology, and do not serve to buttress the identity of forces in nature (the identity of which in any case lies in the construction of matter) but rather to identify unites of natural activities with those of transcendental ones" (Grant 2006: 151). The closing comment of the Ideas is apt here as well: "that path into the true interior whereby we penetrate at last to the most perfect knowledge of the divine nature, in reason, as the indifference where all things lie in equal weight and measure as one, and this veil in which the act of eternal producing is clothed, itself appears dissolved in the essence of absolute ideality" (Schelling 1988: 273).

Where nature recedes into a point of indifference it is an instance of forces, of the recession of forces from us, which we can only see as a brief glimpse of stability. In ideality, that moment is productive as an absolute ideality because it becomes a conceptual brick of formal or functional construction. Where nature appears to have 
taken a rest, where polarities and forces seem to briefly calm their havoc, an object emerges, nature becomes an instance of construction, of moving forward with the construction of a nature that is free but that allows for, at least as a sufficient condition, the advent of our thinking. In morbid terms, the construction of nature comes to us through the corpses of its becoming, which we arrange into new experiments and which we open to find (as far back as we can discern) the engines that produced that particularity.

The chemical forces then appear as the contingency of the dynamism of nature, illustrating but not reducible to, the deeper, absolutely necessary, forces of dynamism as such (1988: 148). Chemistry here functions as the middle ground between absolute necessity and radical contingency.

Schelling's articulation of contingency is placed against Hegel's philosophy as a science of reason, a science that never manages to get to real existence, according to Schelling (2007: 129-31). This relates to other uses of contingency in Schelling, where the term is related not only to necessity but to essence. This is due to the simple fact that as primal becoming, being is not, it is not inert being, but is potency and therefore the primal essence contains contingency within it (Schelling 1994: 116-17). The issue becomes separating contingency and necessity in nature from that of the mind, which relies on the operative power of the transcendental.

Grant's critique of the First Outline is that Schelling does not give an adequate account of the transcendental that takes shape in the System of Transcendental Idealism and that operates with the First Outline (2006: 151). In both the First Outline and in the Ideas, one could claim that the transcendental is merely invoked in a Kantian sense, either as epistemological limitations (particularly in the Ideas) or as a failed attempt at understanding nature on the whole in the First Outline, as Schelling merely states that the task of the Naturphilosophie is to explain the ideal by the real (Schelling 2004: 194).

In the second book of the Ideas, Schelling writes "chemistry, through a consequence of dynamics, is nevertheless wholly contingent in relation to that science, and can, and can demonstrate its reality simply and solely through experience" (1988: 221-22). What does Schelling mean by this? In part it is the fact that the chemical process makes a crucible of the organic body, perforates the flesh with the acidity of the chemical process as conducted by nature. Schelling takes this concept of a radical chemical affinity from Buffon (Ibid: 208, 210).

Chemistry, then, could be taken to be this process, insofar as it is apprehended by the synthetic grasp of ideality of thought. In 
an interview entitled "The Chemical Paradigm" (2012), Grant addresses the status of chemistry vis-à-vis Naturphilosophie and the other sciences. Grant argues that Schelling's chemistry, following Lavoisier, is a process of analysis and synthesis and never a game of elements (Ibid: 47); it is, as already mentioned, without bottom (Ibid: 50). While physics represents a more base level than chemistry, the field of chemistry and the field of physics are synthetic to the point that they do not cross each other's borders (or such border crossing is minimized for the sake of disciplinarity [Ibid: 57]). The test of such disciplinarity regarding the sciences, according to Grant, should be the same as that for philosophy, that of the extensity test (Ibid: 59). How much coherency can a field have while being as extensive as possible?

That is if extensity is what is, and it is an extensity that is unconditioned (the isness of being) (Schelling 2004: 13), then construction, or chemical construction is the permeating and forming (that is forming and deforming) of a particular body (these particularities being a result of the infinite self-inhibition of nature) (Ibid: 15-16). Or, as Grant argues in the same interview, the universe cannot consist of particulars if there is no bottom or no top to the possibilities of synthesis both thinkable and unthinkable (Grant 2012: 65). To return to chemistry and its relation to necessity and contingency, Grant writes in the same interview: "if contingency is necessary for any nature that is possible, then necessitation takes place within a given nature such that in that nature it ceases to be possible to be produced otherwise than, in fact it is" (Ibid: 77-78). That is, in other words, chemistry cannot undo the non-chemical conditions of its advent functioning as a temporal or historical necessity, but contingently operates and produces contingencies for itself and for future grounds of both thinking and forms of nature.

To quote again from the Ideas: “The purest exercise of man's rightful dominion over dead matter, which was bestowed upon him together with reason and freedom, is that he spontaneously operates upon nature, determines her according to purpose and intention, lets her act before his eyes, and as it were spies on her work. But that the exercise of this dominion is possible, he owes yet again to Nature" (Schelling 1988: 57).

As far as the practice of chemistry goes, Schelling has few kind words in On University Studies, saying that chemistry has subordinated physics and is not equipped (unlike in his Naturphilosophie) to come up with theories of unity. This seems to negate Schelling's enthusiasm for French chemistry, which seemed to drastically change his perception of the ungrounded chemical process and its relation 
to dynamics. In the Ideas, Schelling seems to curb chemistry's ability to theorize while acknowledging its capacity for experimentation (Ibid: 218). For Schelling, at least in the Ideas, chemistry requires a firmer relation to physics as well as mathematization to secure its non-chemical ground.

But this task seems to be pushed slightly aside for organicity in the First Outline.

Schelling (2004: 173) names intussusception (the term taken from an intestinal folding together or telescoping) as the cause of the chemical process, of the two attempting to collapse into the one - and irritability is organized electricity just as reproduction is organized chemical process. The liquefaction of the chemical process, as already mentioned, asserts that the cause of the chemical process cannot be subordinate to it as the chemical process would dissolve that cause as well (Ibid: 175). Chemistry is always between heterogeneities (Ibid: 174), and that which is chemically indecomposable must be the building block of the chemical domain as already suggested (Schelling 2004: 176).

In the First Outline, Schelling ultimately brings chemistry to the bodily (to the organism) whereas in the Ideas he is more concerned with the relation of chemistry to physics (though this receives some focus in the First Outline). Chemistry may seem to be left in the cold, but where chemistry plays its most useful, if not always direct, role is in relation to Schelling's epistemological and empirical apparatuses.

In his essay "The Chemistry of Darkness" (2000), Grant critiques Hegelian idealism in light of Schelling's "unconditional empiricism" via the chemical reducibility of the ideal (Ibid: 43-45), following on from Schelling's definition of chemistry in the Ideas as sensory dynamics. As Grant sums it up: "Insofar as mind is productive, it maintains contact with the blind forces of unconscious production that is nature; insofar on the other hand, as it seeks to apprehend itself as product, it isolates its productivity in its self reflection" (Ibid: 49). Here again we have the double series, but, for the sake of the chemical and of chemistry as sensory dynamics (as Schelling defines it in the Ideas), we find that chemistry deepens the possibility and meaning of empiricism for us in the wake of nature's productivity and its products. Since creatures are merely fixed chemical processes, sensibility is the mark of unity in nature as it affects us, where irritability is the mark of nature's continuity as it affects us. This ground appears as a darkness but is also productive as it simultaneously indexes our natural being (as productive, as always becoming) and our apparently unnatural (though still due to nature) capacity for thought. In nature, the organism is merely 
a self-relating chemical process, this process we ideally experience as sensibility and irritability on the first order and epistemology on the second order.

As Grant puts it in Philosophies of Nature after Schelling: "the emergence of the generated world challenges the senses to exceed their own genesis" (2006: 44) toward the Idea but never able to grasp it. Thought is shaped by the force effects of the universe as a tensioned absolute. Schelling's absolute or cosmos is a plane in which thought and being are not formally articulated by structures of reason but are blearily mashed, "the mixtures of Idea, matter, being and not being are necessarily ideal and material and therefore neither are nor are not, but by nature, the becoming of being" (Ibid: 45). Or, as it is argued in the System of Transcendental Idealism, every activity must have a ground outside of it (Schelling 1978: 101). Or as Grant puts it in more heavy ontological terms: "If being is necessarily indeterminate, then this indeterminacy must precede its determination, since the converse would entail that being is determinate in advance of its determination" (Grant 2009: 449). That is, any science of the present is determines a synthetic past and synthetic future in both ideal and real regimes.

Chemico-philosophy, or Naturphilosophie via chemistry denotes everything is synthetic yet this synthesis does not reabsorb the anteriority and contingency that thought cannot hold due to the anteriority of nature induced by production of production, but replays the dynamism, however hollowly, through productive thinking. Thought is a model of itself attempting to model non-thought, with the conceptual being the quantification of this replay. As thinking beings, we are caught in the nature of thought, which, while we can acknowledge its anterior limitations, seems limitlessly forward, though never completely free as it is bound by its own material genesis as well as the history of ideas which have preceded it. As Christopher Lauer argues in his text The Suspension of Reason (2010: 41), Schelling effectively dehumanizes epistemology as it becomes the self-relation of a disequilibrium of forces. This means that, as mentioned above, if chemistry implies sensibility or epistemology, then it seems increasingly less a human privilege.

As we self-isolate our thinking from the chemical barrages of the environment, or even from what we have consumed on any particular day, or carcinogens, or inhalations, or bad smells, the chemical is that simultaneous darkness yet productivity. Our physiology changes that which affects the physiology of the mind and shapes our empiricism. The fact that we know this reshapes our thinking, the fact that we reflect upon possible changes to us from an un- 
known externality, causes an ideally caused change in our ideas. In the Ideas, Schelling writes: "The Ideal world presses mightily toward the light, but is still held back by the fact that Nature has withdrawn as a mystery. The very secrets which the ideal harbors cannot truly become objective save in proclaiming the mystery of Nature" (1988: 53-54).

These forms of darkness that are always falling into the past are complicated by an epistemological figure of Schelling, namely his odd image of self-consciousness as the lamp of the whole system of knowledge that casts its light ahead only, not behind (Schelling 1978: 18). This light, as the scalpel of the chemical, combined with the ground of existence as a primordial night or the storm of Platonic matter - the darkest of all things (Schelling 2006: 30), or "the reef of matter" where philosophers are shipwrecked (Schelling 1988: 179), or an infinitum of grounds (Schelling 1978: 102), or nature's strangeness before reason (Schelling 2007: 137); all demonstrate the simultaneous difficulty and necessity of keeping substance as only ever a impermanent place holder.

Yet if this is the case then it would seem that the progress or even simply the history of chemistry could not be written in the substances or objects it had claimed to discover, since some of these objects ceased to be, or never were, or will be proved not to be. But it is not the case either that chemistry is simply the history of chemical ideas in the mind entertained by our human practices.

\section{DeLanda and Chemical Sense}

Manuel DeLanda's recent work has moved deeper into the fields of history and philosophy of science, while still maintaining a general continental (especially Deleuzian materialist) attitude toward philosophy. Following from his text on synthetic philosophy Philosophy and Simulation (2011), DeLanda's most recent text, Philosophical Chemistry (2015) attempts to track a complex genealogy of chemistry that tends toward a realist account. DeLanda's analysis of the history and generation of the field of chemistry avoids both a hard realist articulation of a scientific field (as one might find in ontic structural realism) as well as an overly social-constructivist account (whether in a Latourian or Kuhnian fashion).

DeLanda argues that chemistry and other sciences are composed of four components: a domain of phenomena, a community of practitioners, a set of instruments and procedures, and a culture (DeLanda 2015: ix-xi). All of these components, which interact and shift over time, compromise the field of chemistry. In the case of 
classical chemistry (1700-1800), for example, the phenomena was defined as primarily concerned with substances and reactions (Ibid: 2-3), practiced by alchemists and nature philosophers, using rudimentary instruments, and in a generally unofficial culture, one of competing individual sciences without much proper academic recognition. As hinted above, in the history of chemistry, Kant, and Schelling after him, were theorizing chemistry during the transition between classical chemistry, organic chemistry, and physical chemistry (1700-1850). However, that any discussion of the role played by natural philosophy generally (and the German Naturphilosophie in particular) is absent from DeLanda's text appears somewhat strange.

The fact that any discussion of Kant is absent from DeLanda's text may not appear completely surprising in the context of a history of philosophy, but it does appear somewhat odd given the particular relation that DeLanda builds between constructivism and realism. Kant is mentioned in passing in a note as someone who dismissed chemistry because of its lack of a "mathematical backbone" (DeLanda 2015: 147). In the related footnote, DeLanda doubts Kant's emphasis on the synthetic a priori and claims that Kant's arguments are merely "outdated" (Ibid: 218). Yet, as we have seen in both Friedman and McNulty's work above, this gives little credit to Kant and, furthermore, only focuses on the Metaphysical Foundations, thereby ignoring everything that followed.

We might even venture to say that the a priori standard for Kant's rejection of chemistry actually brings him far closer to Gilles Deleuze than DeLanda might wish to admit, since the sciences that Deleuze chooses to valorize are those that stand up to his metaphysical a priori of radical difference and are not judged relative to the history of the sciences or to some other mark of epistemological success.

But perhaps this is all less surprising once we take DeLanda's philosophical past into account. While Deleuze and Guattari do not explicitly appear in the text, DeLanda is following their broadly Aristotelian trajectory into contemporary materialism (2015: 164-65). ${ }^{4}$ As a result, however, DeLanda caricatures idealism in a pre-Kantian way and sets up an opposition between actual and ideal that itself appears somewhat dated (Ibid: 101-02).

But Schelling's idealism in which ideas and concepts are as natural as stones and birds does not fit into DeLanda's caricature, putting pressure on the Deleuzian image of thought relative to the effects of the chemical on the physiological and the physiological

${ }^{4}$ One such clear instance of DeLanda's continuing Deleuzian alliance is evident in his discussion of diagrams as fundamentally analogical tools, an argument quite central to Deleuze's thought. 
on the chemical. In this regard, the title of DeLanda's text is one of the more perplexing features since, on the face of it, there seems to be little discussion of philosophy generally, or even philosophy of science (save for the final chapter). In some sense, the relation between theory, or concepts in general, and scientific practices (in terms of extra-experimental claims) is not too clear, that is, it seems that concepts emerge only after practice. While this has much truth to it, it does not do adequate justice to more speculative claims in the way they direct the kinds of experimental practices pursued.

This can be analyzed in a positive and negative sense. The positive sense, and one that is remarkably well executed in DeLanda's text, is that of demonstrating a progressive model of science with little or no stereotypical Enlightenment mythos (thereby avoiding a Whiggish conception of scientific history). That is, DeLanda does an excellent job of explicating how the sciences generally, and chemistry in particular, gradually become objectively better at delimiting the actual domain of nature without this seeming like inevitable progress. It may be that DeLanda's careful, detailed, and non-catastrophic (or non-Kuhnian) approach might appear to disallow any reliance upon purely, or mostly, conceptual interruptions in the historical analyses of the collective and experimental development of cognitive tools and experimental practices.

DeLanda's emphasis on construction or synthesis is not deployed in a socially constructivist manner but relies upon (an increasingly strained) dependence on Deleuze. The utilization of Deleuze's work poses problems for an analysis of science that is historically focused on DeLanda's later work. This is in part due to an emphasis on the concept that is not sufficiently abstracted from the heroic figure of the scientific genius (and this is also evident in Georges Canguillem and Jean Cavailles). DeLanda seems to compensate for this with historical details.

One other troubling and related issue around the fact that DeLanda sees a debate of atomists and non-atomists as one in which the atomists won (DeLanda 2015: 72). But does this not limit the debate in an odd way since the status of chemistry itself was so open? The non-atomists were touching upon issues in thermodynamics and in field-physics which, may not be considered purely chemical now, or a matter strictly for chemistry, they were relevant then. Does a progressive model in terms of processes, instruments, and cultures, have as strong a bearing on the conceptual ideas that may later be proved to be true?

For instance, DeLanda points out that synthesis lagged behind analysis until the production of synthetic biological compounds 
such as urea in 1828 (Ibid: 65), which entailed biological organisms being treated as laboratories for synthesis (Ibid: 71). But this seems to place conceptual work as a mere afterthought of practice, one that only springs from the experimental result and has very little role in forming and enacting the various experimental attitudes as such.

Looking back at the work of philosophers of science such as Friedman and Michela Massimi, the strictly, or largely social dimension of the function of construction is unhelpful. Even a minimal degree of Kantianism here seems apt to formulate a more nuanced account of experimental consciousness and its relation to experimental practice. Several of the Romantic scientists and the Naturphilosophen used their own bodies as experimental objects (or other organisms) long before 1828. Ritter, already been mentioned several times, destroyed himself through experiments centered on subjecting himself to electrical currents and various chemical substances in order to see whether normative perception was as formally rigid as Kant had suggested.

It is here that Kant and Schelling's articulation of synthesis can be taken up as emphasizing the sensorial aspect of the chemical and the chemical gradients of sense. While from DeLanda's perspective this can be read as forcing a rationally epistemological wedge between various registers of sense, for Kant and for Schelling the epistemological (though in quite different degrees) reshapes the bounds of sense in radical ways, but, for the latter, one can argue that chemical research constantly updates that which we take to be the transcendental.

DeLanda's immanent historical approach depends upon a close relation between the empirical or the sensoral and the thinkable, following on from Deleuze. This would seem to bring him close to a Schellingian position, but there is in fact a stark difference between an immanent approach and one that relies on an, albeit naturalized, form of the transcendental. For Deleuze, and by extension for DeLanda, the discoveries of the sciences cannot rewrite or deeply perturb the structure of the mind as the structure of the mind and the experiences of sense must be always tightly knit-this is the demand of Deleuze's empiricism. The transcendental, in Schelling's formulation, is the formal grasp of a moment in which the derangement of the mind lays bare the insufficiency of our grasp of the concept that is not our creation alone.

DeLanda's emphasis on a community of practitioners, a set of instruments and procedures, and a culture is a rather straightforward approach in doing the history of science. Nicholas Jardine (2000) for instance focuses on communities, techniques, methods, and local questions, and more sociological and anthropological approaches 
have set out to deploy similar interpretative matrices. What the Romantic sciences and the Naturphilosophen emphasized was the possibility of autonomous concepts that were not to be wedded to the individual genius scientific or philosophical or to be merely subsumed in the practical or pragmatic work of experimentation. Again, this is dramatized most extremely in the treatment of one's own body as a site of experimentation.

But this is a far cry from a Deleuzian experimentalism of the body, nor is it a historical program that relies on rational progression or socially deconstructed networks of influence. Schelling's chemical philosophy is experimentalist-pragmatic but with the complication that such experimentation rewrites the cognitive agents performing the experiments. Hence there can be no heroic singular bearer of the concept. A community of researchers is not only the constructive power of a collective mind but the only mind that remains relatively consistent, or at least with enough memory to retain the conceptual force of what has occurred.

\section{References}

Beiser, Frederick (1993). The Fate of Reason: German Philosophy from Kant to Fichte. Cambridge, MA: Harvard University Press.

Boyle, Robert. (2013) The Sceptical Chymist. Courier Corporation.Mineola, NY: Dover Publications, Inc.

Cobb, Cathy, and Harold Goldwhite (202). Creations of Fire: Chemistry's Lively History. New York: Springer.

DeLanda, Manuel (2015). Philosophical Chemistry: Geneaology of a Scientific Field. New York: Bloomsbury Academic.

Friedman, M. (2007). “Kant - Naturphilosophie - Electromagnetism.” In Hans Christian Ørsted and The Romantic Legacy In Science, eds. Robert Michael Brain, Robert S. Cohen, and Ole Knudsen, 135-58. Dordrecht: Springer.Grant, Iain Hamilton (2000). “The Chemistry of Darkness.” Pli 9: 36-52.

Grant, Iain Hamilton (2006). Philosophies of Nature After Schelling. London: Continuum.

Grant, Iain Hamilton (2009). "Prospects for Post-Copernican Dogmatism: The Antinomies of Naturalism.” Collapse: Philosophical Research and Development V: 415-54.

Jardine, Nicholas (2000). The Scenes of Inquiry: On the Reality of Questions in the Sciences. Oxford: Oxford University Press.

Kant Immanuel (2002). Critique of the Power of Judgment. Trans. Paul Guyer. Cambridge: Cambridge University Press.

Kant, Immanuel (2004). The Metaphysical Foundations of Natural Science. Cambridge: Cambridge University Press.

Kant, Immanuel (1993). The Opus Postumum. Trans. Eckhart Forster and Michael Rosen. Cambridge: Cambridge University Press.

Lauer, Christopher (2010). The Suspension of Reason in Hegel and Schelling. London: Continuum.

Schelling, F. W. J. (1965). On University Studies. Trans. E. S. Morgan. Athens: Ohio University Press.

Schelling, F. W. J. (1978). System of Transcendental Idealism. Trans. Peter Heath. 


\section{Ben Woodard}

Charlottesville: University Press of Virginia.

Schelling, F. W. J. (1988). Ideas for a Philosophy of Nature. Trans. Errol Harris and

Peter Heath. Cambridge: Cambridge University Press.

Schelling, F. W. J. (1994). Idealism and the Endgame of Theory. Trans. Thomas Pfau. Albany: State University of New York Press.

Schelling, F. W. J. (2002). Clara or, On Nature's Connection to the Spirit World. Trans. Fiona Steinkamp. Albany: State University of New York Press.

Schelling, F. W. J. (2004). First Outline of a System of the Philosophy of Nature. Trans. Keith Petersen. Albany: State University of New York Press.

Schelling, F. W. J. (2006). Philosophical Investigations into the Essence of Human Freedom. Trans. Jeff Love and Johannes Schmidt. Albany: State University of New York Press.

Schelling, F. W. J. (2007). The Grounding of Positive Philosophy: The Berlin Lectures. Trans. Bruce Matthews. Albany: State University of New York Press.

Woodard, Ben (2019). Schelling's Naturalism: Space, Motion, and the Volition of Thought. Edinburgh: Edinburgh University Press. 